\title{
High Aiming in Public Sector Marketing: A Way Forward to Boost China's Economy
}

\author{
Ahmad Nawaz Zaheer \\ Song Wei ${ }^{*}$ \\ Ren Chong \\ Muhammad Abdullah \\ Kashif Ullah Khan

\begin{abstract}
School of Public Affairs, University of Science and Technology of China, Hefei 230026, Anhui China Corresponding Email: songwei@ustc.edu.cn; anzaheer@mail.ustc.edu.cn University of Science and Technology of China, (School of Public Affairs, University of Science and Technology of China Hefei 230026, Anhui China ), Muhammad Abdullah (Department of Economics, Gomal University D.I.Khan Pakistan
\end{abstract}

\section{Doi:10.5901/mjss.2015.v6n6p107}

\section{Abstract}

The importance of marketing in successful business cannot be overemphasized. In China, focused and accentuated public sector marketing has enabled the government to timely address the emerging needs of public as well as inspired entrepreneurism which has brought significant reforms in the whole society. This study presents an in-depth analysis of public sector marketing in China. Our findings shows that benefits of good marketing i.e. output has significant positive relationship with planning of marketing activities $(\beta=0.218, p=0.012)$ and culture $(\beta=0.202 ; p=0.005)$. Besides these, organization and management also had significant effect on marketing output. We conclude that progressive marketing activities in public sector of China will provide the best solution to overcome the challenges faced by the largest economy of the world.

Keywords: Public oriented, Reforms of Society, Public Sector Marketing

\section{Introduction}

Marketing has been a basic practice and remains major function in business. Currently when government wants to be more receptive and try to accomplish the wants of the community, marketing plays its very important role and help government to deal with this goal. Marketing has been increasingly being practiced by the public sector in various European countries as well as in the USA. Public oriented government always use that marketing concepts with match up their services and product with public requirements. American Marketing Association which is one of the leading of professional marketers, defined as "Marketing is the process to planning and executing the conception, pricing, promotion and distribution of ideas, goods and services to create exchanges that satisfy individual and organizational objective." Judith J. Madill argued that the satisfaction and exchange are two foundation factors of marketing. In order to create exchanges with consumers and the business itself; which is the primary goal of the business, marketing approach needs to be adopted. In their book 'Marketing in the public sector, A Road map for improved Performance', Philip Kotler and Nancy Lee have discussed the expectations of both Government and consumers regarding performance and efficiency comparable to private sector. According to them, "The public sector needs to improve its performance to raise the public's confidence and satisfaction and thereby their support". To address this issue, performance of public agencies can be improved by adopting marketing tools being used by the private sector. Despite the importance of public sector marketing, as emphasized by Kotler and Lee, a group of people are of the opinion that these tools are not necessary since the government is inherently different in their business operations. In fact, "these differences are often exaggerated and should not be used as an excuse for inefficiency, ineffectiveness or waste", commented by Kotler and Lee.

In late 1960s, Sidney J. Levey and Philip Kotler argued that marketing is not just a business function; it is rather a valid function for non-business organization as well. All organizations have marketing problems and they need to understand marketing (Kotler and Levy 1969). Furthermore many academic marketers criticized this and claimed that marketing made sense only in profit oriented enterprises. Later on, many marketing professors found the idea stimulating and without necessarily agreeing that it was valid, began to study and experiment with it. 
More articles were published in 1970s, discussing applications of marketing technology to various areas for example; public transportation, population problems, health services, fund raising, religion and arts organizations etc. The only text book which had covered all above topics was appeared in 1975 under the titled Marketing for Nonprofit Organization. Furthermore, Gaedeke (1977) published a book of readings, Lovelock and Weiberg (1977) a book of cases, Lovelock (1977) a bibliography of over 100 cases, and Nichels (1978) a general marketing textbook discussing equal attention to business and non-business marketing.

Cousins (1990) has discussed briefly that during the early 1990s, many of the European countries already practiced and adopt the marketing tool in their operation and they also acknowledged this concept that the citizen as customer. Severijnen and Ter Braak,(1992) highlighted that in public sector "marketing surveys" which help the administration to evaluate citizen 's necessities, likewise an imperative utilization of marketing methods, reviews through city panels to evaluate nationals' necessities (Severijnen and Ter Braak, 1992), informative governance(Damoiseaux, 1991) and social marketing to advance certain social objectives(Kotler and Roberto, 1989 and others). Further Kotler and Roberto,(1989) have also highlighted the use of marketing strategies in public sector and documented that social marketing can always promote the social objectives. Shapiro\& Bespn (1973) contributed in marketing for nonprofit organizations and identified three major marketing tasks of the manger (resource attraction, resource allocation and persuasion) he describes the marketing mix as well. Peter Ducker (1973) has discussed the difference of running a public service and private sector organizations. Private organization can be paid what they produce what customer chasing want but in public sector can be paid out of a budget allocation.

\section{Public Sector Marketing in China}

China is a country with a dominant economic power; having improvements in access to and value of basic public provisions, reduction in the level and scale of poverty. Public sector reforms in China were commenced in 1978, but 1992 was the inflection point. Early in these years, one of the leaders Deng Xiaoping, in his speeches proposed to accelerate the reform process. Later that year, the Fourteenth National Congress of the Communist Party of China confirmed the establishment of a socialist market economy as the county's economic system reform objective setting china on the path of a becoming a transitioning market economy. China has similar significant achievements in public service delivery. In 1978, the central government began to transfer the responsibility of public service delivery to local government, by 1990 public service delivery was positioned as a key component of national development, reflecting the collaborative roles of government. The new concept of public sector marketing in China related researches are very less. Xu Xiaoji (1996) described some counter measures from the macroscopic perspective and recommended that the government should improve their marketing ability from a different perspective. Yu Peng's (2005) analyses regarding the objective condition and importance of government marketing generation also described the government marketing evaluation criterion by combining the characteristics of the Government marketing. Zhu Jing's (2009) analyses, based on the assumption of the Economic Man of Government behavior, analyzed the reason for the system of government marketing that opened up a new way of government marketing theory. So many other Chinese scholars have also described their views about marketing of local government. Li Derong.Gewifen (2002), using the Ningbo's government as an example and discussed about the city marketing. While conducting this survey, we got an impression from the respondents that marketing is merely considered as advertising or promotion. However, in actual terms, marketing is not just a tool to promote some products or services; it is in fact to understand your customer and their needs, stakeholders as well as your competitor, it helps to introduce new products and services with innovation. For the public sector, marketing ends up being the best instrument in giving a stage for public sector that can help to satisfy general society needs and convey the genuine quality. Nearly, public sector is about native fulfillment and qualities, whereas, private sector uses marketing as a tool to accomplish customer satisfaction and values. By adopting marketing strategies, public sector organizations can serve more efficiently in delivering quality products and services.

Further David Osborn in his book, Reinventing Government "How the Entrepreneurial Spirit is Transforming in the Public Sector" discussed that government are gradually fall among declining revenues and expanding burden for services. In this case marketing is the best option for the government in order to meet the future challenges.

\section{Research Methodology}

We used Spearman Correlation Coefficient to disclose the strength/degree of association between the target variables. 


$$
\rho=\frac{\sum_{i=1}^{n} \sum_{j=1}^{m}\left(X_{i}-\bar{X}\right)\left(\mathrm{Y}_{j}-\bar{Y}\right)}{\sqrt{\sum_{i=1}^{n}\left(X_{i}-\bar{X}\right)^{2} \sum_{j=1}^{m}\left(\mathrm{Y}_{j}-\bar{Y}\right)^{2}}}
$$
marketing.

In this study our target variable are Culture, Planning, Management, Organization and output in public sector

Further we applied Multiple Linear Regression Model to sort out the degree of dependency of our dependent/Response variable.

$$
\begin{aligned}
& Y_{i}=\beta_{0}+\beta_{j} X_{j}+\omega_{k} \\
& i=1,2 \\
& j=1,2,3, \ldots, 7
\end{aligned}
$$

We can also write it as

$$
Y_{i}=\beta_{0}+\beta_{1} X_{1}+\beta_{2} X_{2}+\beta_{3} X_{3}+\beta_{4} X_{4}+\beta_{5} X_{5}+\beta_{6} X_{6}+\beta_{7} X_{7}+\omega_{k}
$$

Where $Y_{i}$ is the dependent variable and $Y_{1}$ is for output and result.

Where $X_{1}$ independent variables and $X_{1}$ is for culture, $X_{2}$ for Planning, $X_{3}$ for Organization and $X_{4}$ for Management. Further we also applied the factor analyses to observe the contribution of Independent variables.

\section{Research Variables}

James Mintz (2006) briefly discussed the public sector marketing. In his article "The Case for Marketing in the Public Sector" he explained the various factors that can gauge the marketing level in any public sector organization. After studying the various literature and as well as above mentioned article we were able developed the following variables which were being measured with five-level Likert scales.

\subsection{Culture}

This variable explains and accesses the culture of the organization more specifically regarding marketing activities in public sector. It explains about the senior management's familiarity of marketing and commitments, their understanding of marketing and prioritizes their customers. The management within organization pay attention to develop latest as well as best approaches to serve the customer.

\subsection{Organization}

This variable expresses the organization by overall responsibility to carry out marketing activity. It indicates the specific marketing position which is responsible to carry out marketing activities and understanding marketing management with their heads. It describes the relationship between marketing staff and operational staff and also indicates the presence of the marketing function

\subsection{Planning}

This variable shows the marketing planning advancement which, at the authoritative level, is connected with the mission. It shows the association with characterized arranging from brand methodology with quantifiable marketing target. Keeping in mind the end goal to satisfy the needs, a marketing spending plan in view of recognized methods and adaptable plans are needed.

\subsection{Management}

In order to develop new products and services, there is a defined process in executing high value ideas, communicating the value of products and services, relationship with stakeholders in delivery as well as reasonable fee as per usage not to just cost-recovery. Stakeholders' experience is also taken into account to ensure the consistency among services delivery channel. 


\subsection{Output}

This variable indicates the output from the marketing efforts. It consists of new clients' attraction towards offered programs and services. High standards in customer satisfaction, revenue generation, increase in the funding sources as well as measurable impact on behaviors and delivering unique and high valued products, programs and services.

The main objective to conduct this research work was primarily with an aim to identify the key marketing activities in China and examine their relationship to indicate ongoing as well as future trends based on the variables selected for the study. We aimed in study this study is to portray the impact of every variable on marketing endeavors furthermore the commitment of every variable in marketing activities.

The main reason of choosing this study is that academically there is less work done in this field especially in public sector of China. China is a country with a dominant economic power; having improvements in access to and value of basic public provisions, reduction in the level and scale of poverty China is fast growing country and having the tope on its economic level, Chinese public sector have so many successful stories which need to identified and document.

\section{Survey Methodology}

To access the public sector marketing in China, respondents views related to several statements were recorded. Those were related to various aspects of their organizations' approach to the marketing management. Culture of adopting good marketing practices by their organization was surveyed. An aggregate of 300 surveys were disseminated in two different cities of Anhui province, China. Out of these, 225 samples were successfully collected.

\section{Empirical Results}

Table 1: Reliability Statistics

\begin{tabular}{|l|c|c|}
\hline Research Variables & Cronbach's alpha & No.of Items \\
\hline Culture & .89 & 5 \\
\hline Organization & .92 & 4 \\
\hline Planning & .93 & 5 \\
\hline Management & .93 & 7 \\
\hline Output & .80 & 6 \\
\hline Altogether in data & .86 & \\
\hline
\end{tabular}

Cronbach's alpha value of 0.86 shows significant consistency within the specific sample.

Table 2: Correlations Test

\begin{tabular}{|c|c|c|c|c|c|c|}
\hline & & Output & Culture & Planning & Management & Organization \\
\hline Output & $\begin{array}{l}\text { Pearson Correlation } \\
\text { Sig. (2-tailed) } \\
\text { N }\end{array}$ & $\begin{array}{c}1 \\
225\end{array}$ & & & & \\
\hline Culture & $\begin{array}{l}\text { Pearson Correlation } \\
\text { Sig. (2-tailed) } \\
N\end{array}$ & $\begin{array}{l}.485 \\
.000 \\
225\end{array}$ & $\begin{array}{c}1 \\
225\end{array}$ & & & \\
\hline Planning & $\begin{array}{l}\text { Pearson Correlation } \\
\text { Sig. (2-tailed) } \\
N\end{array}$ & $\begin{array}{l}.578 \\
.000 \\
225\end{array}$ & $\begin{array}{l}.481 \\
.000 \\
225\end{array}$ & $\begin{array}{c}1 \\
225\end{array}$ & & \\
\hline Management & $\begin{array}{l}\text { Pearson Correlation } \\
\text { Sig. (2-tailed) } \\
\text { N }\end{array}$ & $\begin{array}{l}.492 \\
.000 \\
225\end{array}$ & $\begin{array}{l}.527 \\
.000 \\
225\end{array}$ & $\begin{array}{l}.597 \\
.000 \\
225\end{array}$ & $\begin{array}{c}1 \\
225\end{array}$ & \\
\hline Organization & $\begin{array}{l}\text { Pearson Correlation } \\
\text { Sig. (2-tailed) } \\
N\end{array}$ & $\begin{array}{l}.555 \\
.000 \\
225\end{array}$ & $\begin{array}{l}.504 \\
.000 \\
225\end{array}$ & $\begin{array}{l}.776 \\
.000 \\
225\end{array}$ & $\begin{array}{l}.458 \\
.000 \\
225\end{array}$ & $\begin{array}{c}1 \\
225\end{array}$ \\
\hline
\end{tabular}

**. Correlation is significant at the 0.01 level (2-tailed).

Individual relationship of above target variable demonstrate that the quality of relationship between the variables is high 
and the correlation coefficient is additionally exceptionally essentially not quite the same as zero $(p<0.001)$.

Table 3: Regression analyses (Model Summary)

\begin{tabular}{|c|c|c|c|c|}
\hline \multicolumn{1}{|c|}{} & \multicolumn{2}{|c|}{} \\
\hline Model & $\mathrm{R}$ & R Square & Adjusted R Square & Std. Error of the Estimate \\
\hline 1 & $.485^{\mathrm{a}}$ & .235 & .231 & .77513 \\
\hline 2 & $.624^{\mathrm{b}}$ & .390 & .384 & .69386 \\
\hline 3 & $.635^{\mathrm{c}}$ & .403 & .395 & .68767 \\
\hline 4 & $.647^{\mathrm{d}}$ & .418 & .408 & .68052 \\
\hline
\end{tabular}
a. Predictors: (Constant), Culture
b. Predictors: (Constant), Culture, planning
c. Predictors: (Constant), Culture, planning, organization
d. Predictors: (Constant), Culture, planning, organization, management

By looking into the above model synopsis (Table3) especially the estimation of R-square, this measurement lets us know how significantly of the variety in the estimation of the needy variable is clarified by our regression model. By relapsing result on culture, planning, organization and management an R-square of 0.42 , this shows that 42 percent of the variety in the yield can be clarified by variability in culture, planning, organization and management

Table 3.1: ANOVA

\begin{tabular}{|c|c|c|c|c|c|}
\hline Model & Sum of Squares & $d f$ & Mean Square & $\mathrm{F}$ & Sig. \\
\hline Regression & 41.110 & 1 & 41.110 & 68.423 & $.000^{\mathrm{b}}$ \\
\hline 1 Residual & 133.985 & 223 & .601 & & \\
\hline Total & 175.096 & 224 & & & \\
\hline Regression & 68.215 & 2 & 34.107 & 70.843 & $.000^{c}$ \\
\hline 2 Residual & 106.881 & 222 & .481 & & \\
\hline Total & 175.096 & 224 & & & \\
\hline Regression & 70.588 & 3 & 23.529 & 49.757 & $.000^{d}$ \\
\hline 3 Residual & 104.507 & 221 & .473 & & \\
\hline Total & 175.096 & 224 & & & \\
\hline Regression & 73.212 & 4 & 18.303 & 39.522 & $.000^{\mathrm{e}}$ \\
\hline 4 Residual & 101.883 & 220 & .463 & & \\
\hline Total & 175.096 & 224 & & & \\
\hline
\end{tabular}
a. Dependent Variable: Output
b. Predictors: (Constant), Culture
c. Predictors: (Constant), Culture, planning
d. Predictors: (Constant), Culture, planning, organization
e. Predictors: (Constant), Culture, planning, organization, management

Table 3.1 shows the output of the ANOVA analysis; whether we have a statistically significant difference between our target variables. We can see that the $p$-value is $0.000(p=0.000)$, which is below level of significance $(.05)$ and, therefore, there is a statistically significant association along with all the variables.

Table 3.2: Coefficients Model

\begin{tabular}{|c|c|c|c|c|c|}
\hline \multicolumn{6}{|c|}{ Coefficients $^{a}$} \\
\hline \multirow{2}{*}{ Model } & \multicolumn{2}{|c|}{ Unstandardized Coefficients } & Standardized Coefficients & \multirow{2}{*}{$\mathrm{t}$} & \multirow{2}{*}{ Sig. } \\
\hline & B & Std. Error & Beta & & \\
\hline (Constant) & 1.562 & .262 & & 5.967 & .000 \\
\hline Culture & .537 & .065 & .485 & 8.272 & .000 \\
\hline (Constant) & .997 & .246 & & 4.051 & .000 \\
\hline 2 Culture & .298 & .066 & .269 & 4.490 & .000 \\
\hline Planning & .427 & .057 & .449 & 7.503 & .000 \\
\hline
\end{tabular}




\begin{tabular}{|c|c|c|c|c|c|}
\hline (Constant) & 1.000 & .244 & & 4.101 & .000 \\
\hline Culture & .262 & .068 & .236 & 3.874 & .000 \\
\hline Planning & .301 & .079 & .317 & 3.787 & .000 \\
\hline Organization & .166 & .074 & .190 & 2.240 & .026 \\
\hline (Constant) & .832 & .252 & & 3.308 & .001 \\
\hline Culture & .202 & .072 & .182 & 2.821 & .005 \\
\hline 4 Planning & .218 & .086 & .230 & 2.539 & .012 \\
\hline Organization & .184 & .074 & .210 & 2.493 & .013 \\
\hline Management & .168 & .071 & .163 & 2.380 & .018 \\
\hline
\end{tabular}

By study the coefficients table to determine the value of the constant. This table summarized the results of our regression equation. Column $B$ in the table gives the values of our regression coefficients and the constant, which is the expected value of the dependent variable when the values of the independent variables equal zero.

Here F-value is also significant indicating that our model is good fitted. Which strengthen the result above related with R square. Further By Study the values of the independent variables in the coefficients table. The qualities in column $B$ speak to the degree to which the estimation of that independent variable adds to the significance of the dependent variable. The t-values in the coefficients table designate the variable's statistical importance. Generally t-value of 2 or upper indicates statistical significance. The above result shows that t-value is higher than 2 , so it indicates the statistical significance.

\subsection{Contribution analyses}

Table 4: Communalities

\begin{tabular}{|l|c|c|}
\hline & Initial & Extraction \\
\hline Culture & 1.000 & .567 \\
Planning & 1.000 & .784 \\
Organization & 1.000 & .719 \\
Management & 1.000 & .611 \\
\hline
\end{tabular}

Extraction Method: Principal Component Analysis.

These outcomes demonstrate how a significant part of the fluctuation in the variables has been in charge of by extracted factors. Case in point over $90 \%$ of the fluctuation in yield of marketing activities is represented while $56.7 .5 \%$ of the difference in culture is represented. It is additionally seen as in planning $78.4 \%$, organization $71.9 \%$ and management $61.1 \%$.

Table 4.1: Total variance explained

\begin{tabular}{|c|c|c|c|c|c|c|}
\hline \multirow{2}{*}{ Component } & \multicolumn{4}{|c|}{ Initial Eigenvalues } & \multicolumn{3}{c|}{ Extraction Sums of Squared Loadings } \\
\cline { 2 - 7 } & Total & \% of Variance & Cumulative \% & Total & \% of Variance & Cumulative \% \\
\hline 1 & 2.680 & 67.004 & 67.004 & 2.680 & 67.004 & 67.004 \\
2 & .630 & 15.756 & 82.760 & & & \\
3 & .496 & 12.398 & 95.158 & & & \\
4 & .194 & 4.842 & 100.000 & & & \\
\hline
\end{tabular}

Extraction Method: Principal Component Analysis.

The above table clarified that every one of the variables extractable from the investigation alongside their eigenvalues, the percent of change owing to every component, and the combined fluctuation of the element and the past elements. Notice that the first component represents $67.0047 \%$ of the fluctuation, the second $15.756 \%$ and the third $12.398 \%$. All the remaining components are not huge. 
Table 4.2: Component Matrix

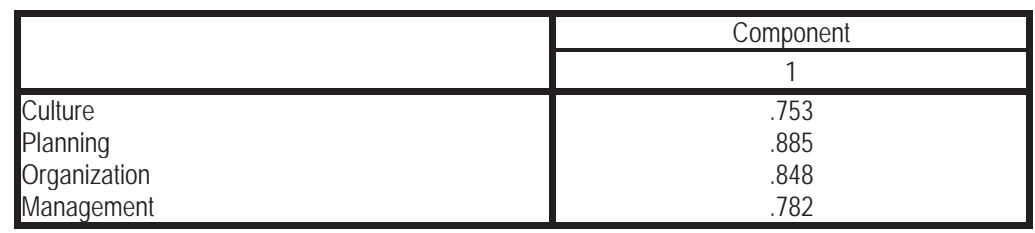

Extraction Method: Principal Component Analysis.

a. 1 components extracted.

The table underneath demonstrates the loadings of the four variables on the one element removed. The higher the supreme estimation of the stacking, the more the element adds to the variable. From this we can analyzed that culture is a variable whose contribution is less than the other variable. On the other side planning having the higher value therefore this factor contribute more to marketing activities in public sector China.

\subsection{Overall findings}

Our results highlight the absence of good marketing practices in the government organizations. Culture, is strongly correlated with output of marketing activities. Empirical result shows that Chinese public sector lacks this culture. A close observation indicates lack in understanding of strategic marketing principles at all managerial levels. Besides lack in understanding marketing skills, people who do apply marketing functions are not skillful in its application. Generally, the specific managerial position for the said task is absent within the organization. Furthermore, the respondents showed their interest and confirmed the presence of marketing efforts in their organization.

Our study suggests that Chinese public sector though good at planning but is less focused in adopting good marketing strategies. In order to satisfy the needs of the customers, identification of innovative programs and services as well as accountability of marketing expenditures are lacking. Surprisingly, the analyses shows that score are very significantly dependent on the various other factors, for example: culture, planning, management and organization. These factors are very important in any public sector and playing important role in the output of marketing activities. We also observed that in Chinese public sector organizations, jobs titled "marketing" are very few in number unlike private organizations. We likewise watched that, dissimilar to private organization marketing where there is a reasonable profession from lower to upper administration, there are not very many positions with "marketing" in the employment title in Chinese public sector. Instead, public sector hiring is not as strongly based on marketing skills as it should be. In any case, Public sector appear to absence of the way of culture and management framework that are essential for marketingcentered organization furthermore critical to get more huge changes yield and aftereffect of marketing activities out in the public sector.

\section{Conclusions}

Our study has clearly indicated public sector marketing as a dynamic factor in China's society. The service oriented government was found closely linked with provision of public goods and services, despite of the fact that budgetary constraint has created several challenges for the government. However, public sector in China has ardently dealt these limitations and brought substantial improvements in the citizen's need as well as creation of new programs for public welfare. Although findings of this study points out that public sector in China is significantly involved in marketing activities; still there is large vacuum to be filled. Therefore, organizations are required to revisit their procedure of developing public oriented products and services. In addition, we conclude that public sector in China possesses huge potential to assist the government in providing effective services for public at large and hence we recommend that government should expand its marketing activities in Chinese public sector. It is high time for the government authorities to be aware of good marketing practices and embrace it whole heartedly. Further research is required to add more factors that can gauge the marketing in public sector of china and to quantify the findings from this research.

\section{References}

"AMA broad approves New Marketing Definition." Marketing news,March1,1985,p.1. 
CEPSM/Phase5,"Setting the Baseline: State of Marketing in the Public and Non-Profit Sectors", (survey,2006)

Cousins, L. (1990). Marketing Planning in the public and non-profit sectors, European Journal of Marketing, 24(7), 15-30.

Drucker, P. F. (1973). "Managing the Public Service Institution," Public Interest, Vol. 33 (Fall), pp. 43-60.

Gaedeke, R. M. (ed.), (1977). Marketing in Private and Public Non-Profit Organizations, Santa Monica, Goodyear Publishing Co.

Kickert,W.J.M.(1997) Public management and Administration Reform in Western Europe,Edward Elgar Cheltenhan,99,15-38.

Kotler, P., \& Andreasen, A. R. (1991). Strategic marketing for nonprofit organizations. 4th ed. Englewood Cliffs (N.J.): Prentice-Hall.

Kotler, Philip and Eduardo L. Roberto. 1989. Social Marketing Strategies for Changing Public Behavior. New York, New York: The Free Press, a Division of Macmillan, Inc.

Madill, J. J. (1998). Marketing in government. The Journal of Public Sector Management, 28(4), 9-18.

Mintzberg, H. (1996). Managing Government, Governing Management. Harvard Business Review (May -June), pp.75-83.

Osborne, D., \& Gaebler, T. (1993). Reinventing government: how the entrepreneurial spirit is transforming the public sector. Harmondsworth: Penguin books.

Philip Kotler \& Nancy $r$ lee. (2007). Marketing in the Public Sector: A Roadmap for Improved Performance. USA: Wharton School Publishing.

Kotler, Philip and Sidney J. Levy. 1969. "Broadening the Concept of Marketing." Journal of Marketing. 33(1):10-15.

Ren, Y. (2005). Local Government Competition: China's intergovernmental relations in the new trend. Humanities magazine, 2005(3): p55 ( in Chinese).

Rosenthal, U. (1995). Publiek partnerschap. Bestuurskunde, Vol. 4(3), 115-21.

Shapiro, B. P. (1973). Marketing for Non-Profit Organizations. Harvard Business Review, 51(1), 123-132.

Shunming, S. (2002), WTO and the strategy of brand management of Chinese government.Administration of China: p40-43(in Chinese)

Star, S. H, Davis, N. J, \& Lovelock, C. H. (1977). Problems in marketing. 5th ed. New York: McGraw-Hill.

Titman, Lionel G \& Civil Service College (1995). Marketing in the new public sector. Pitman Publishing in association with the Civil Service College, London

Walsh, Kieron . (1994). Marketing and Public Sector Management. European Journal of Marketing, 28(3), 63-71. http://doi.org/10.1108/ 03090569410057308

Zaheer, A. (2015). Analyzing Public Sector Marketing in China: A case Study from Anhui Province, China.. Advances In Social Sciences Research Journal, 2(6). Doi: http://dx.doi.org/10.14738/assrj.26.1210 